\title{
Futuristic Approach to Alternative Model Organisms: Hydra Stakes Its Claim
}

\author{
Anbazhagan Murugadas ${ }^{1,2}$, Mohammed Zeeshan ${ }^{1,2}$, \\ and Mohammad A. Akbarsha ${ }^{1,3(\bowtie)}$ \\ 1 Mahatma Gandhi-Doerenkamp Center for Alternatives, Bharathidasan \\ University, Tiruchirappalli 620024, India \\ \{biomuruga23, mdzeesh, akbarbdu\}@gmail.com \\ 2 Department of Environmental Biotechnology, Bharathidasan University, \\ Tiruchirappalli 620024, India \\ ${ }^{3}$ National College (Autonomous), Tiruchirappalli 620001, India
}

\begin{abstract}
The use of mammalian models for toxicological risk assessment of chemicals has been a widespread practice for well over 50 years. This has remained controversial in view of the species differences. Further, the advances in molecular biology techniques have revolutionized the toxicological risk assessment scenario by creating demand for rapid, less expensive and highly relevant methods to risk-evaluate chemical substances quickly. In order to take advantage of these advances the US EPA funded the National Research Council to develop a strategy and vision for toxicity testing in $21^{\text {st }}$ century (Tox 21 ). Tox21 envisions a paradigm shift in toxicity testing and proposes the use of emerging technologies based on non-animal methods for better understanding of chemical-environment interaction, and also emphasizes the adoption of animals belonging to lower levels of taxonomic hierarchy, which are less sentient, in in vivo toxicity testing. Adoption of this shift would perhaps benefit translation of the REACH Legislation, which otherwise greatly relies on animal experiments for chemical risk assessment. We aimed at establishing Hydra, a simple organism belonging to Phylum Cnidaria, as a model organism for toxicity testing of environmental chemicals. Besides, Hydra offers advantages such as easy to culture, reproduces fast, cost-effective and highly sensitivity to inorganic pollutants. Moreover, the whole genome sequence of hydra revealed that most of the genes are conserved in which sense it offers advantage over even in the most routinely used other invertebrate model organisms. We standardized several assay methods which formed the nucleus of several publications. Herein we show that Hydra can be used as a viable bio-indicator for early warning of aquatic pollutants.
\end{abstract}

Keywords: Hydra model $\cdot$ Invertebrate $\cdot$ Toxicity testing $\cdot$ Budding Regeneration $\cdot \operatorname{ROS} \cdot$ Apoptosis 


\section{Introduction}

Chemicals are the basic constituents of living as well as non-living things. Many chemicals naturally occur and many are synthesized. Production and/or consumption/utilization of chemical substances has increased manifold over the period of time, resulting in humans and animals getting exposed to large varieties and volumes of chemical entities directly and/or indirectly. The toxicities of many chemicals are known although thorough risk assessment has not been done for most of the chemicals. This is particularly true of many chemicals belonging to the categories such as nanoparticles and pesticides. Their fate, behavior and adverse effects are not adequately understood, particularly when they exist as mixtures (Geissen et al. 2015). These chemicals, released from the sites of industrial production and/or domestic applications and storage, are carried into the environment through contaminated water, landfill leakage and sewage effluents, and ultimately arrive at the aquatic bodies which, therefore, need special attention (Quinn et al. 2008; Patwardhan and Ghaskadbi 2013; Marchesano et al. 2015). Many chemical substances may degrade as they arrive at the aquatic environment or soon thereafter, whereas the others do not break down easily, so would enter the aquatic organisms and move up the food chain to the higher tropic levels and bio-accumulate, which is a serious threat to the aquatic biota and to the terrestrial animals, including man, which have access to the aquatic ecosystems through the food chain (Murugadas et al. 2016). In view of the adverse effects these chemical substances produce in animals and humans, the lack of knowledge about their behavior and fate, which in turn is due to paucity of sampling and/or analytical techniques, is a big issue. Therefore, multiple actions are required at various levels for risk assessment of chemical pollutants in the aquatic environment (Geissen et al. 2015).

It is generally agreed that health of the ecosystem is measured not only in terms of chemical and physical qualities of water but also in terms abundance and health of biota of the ecosystem (Herricks and Schaeffer 1985). The latter calls for testing of chemical substances per se or the polluted waters in organisms that would in their natural habitat be exposed to such chemicals. In other words, it is better that testing is done in an environmentally related species. However, while fish would fit into this slot, invertebrates should be of preference in the light of uptake of chemical entities from the aquatic environment, by direct ingestion, contaminated preys, water filtration, surface contact and inhalation (Cattaneo et al. 2009). Among the aquatic invertebrates, ones with unlimited supply, small size, simple body plan, and short life cycle, together with that are easy to maintain and cost-effective, and can better be groomed into a suitable model organism. From a regulatory perspective this is highly pertinent and relevant since the US Tox21 vision envisaged adoption of mechanistic models, including nonvertebrate organisms for hazard assessment of chemical substances (Krewski et al. 2010). More recently, the Toxic Chemical Substances Act (TSCA) 1976 of USA has been amended as the "Frank R. Lautenburg Chemical Safety for the $21^{\text {st }}$ Century Act 2016." This revised law includes a new section [4 (h)], entitled Reduction of Testing on Vertebrates has been added, according to which EPA must "develop a strategic plan to promote the development and implementation of alternative test methods and strategies to reduce, refine or replace vertebrate animal testing...", implying encouragement of 
use of non-vertebrate models. Under these circumstances, extensive research has been undertaken in our laboratory to standardize the cnidarian polyp Hydra as a model organism for evaluating the aquatic eco-toxicity of chemical substances and emerging pollutants. Hydra is a small diploblastic organism. It is available in abundance in fresh water bodies. It reproduces profusely by budding, thereby producing identical twins. Hydra has also the remarkable capability to regenerate its amputated body region, making it virtually immortal. It is not known to feel pain and, therefore, does not need an ethical clearance. All cells in Hydra are in close proximity to and contact with the aquatic environment, which facilitates permeation of chemical substances into the animal (Beach and Pascoe 1998). In this paper we present an overview of the assay methods encompassing morpho-physiological features, feeding behavior, growth rate, regeneration, nuclear morphology, cell cycle analysis, apoptosis, and changes at molecular level endpoints for aquatic toxicity testing of chemical entities including nanomaterials.

\section{Hydra-Systematics}

Hydra is a fresh water eumetazoan diploblastic organism belonging to Phylum Cnidaria, Class Hydrozoa, Order Anthomedusae/Anthoathecata, and Family Hydroidea. The body is a cylindrical polyp which is radial. It is essentially a sedentary organism living attached to stones, pebbles and water plants, but can get released from the substratum and swim.

\section{Physiology and Anatomy}

Hydra measures about $10-15 \mathrm{~mm}$ long when fully extended. It is cylindrical and tubular. The oral end of the body column consists of conical hypostome, surrounded by 3-10 tentacles which play role in prey capture, and the aboral end consists of basal disc with which it attaches to the substratum. The body column is divided into four distinctive regions, (i) the gastric region which extends between the tentacle and the first apical bud, where it digests the prey; (ii) the budding section, which produces the bud; (iii) the peduncle, located between the lowest bud and the basal disc; and (iv) the foot region (Hecker and Slobodkin 1976) (Fig. 1). The body wall is comprised of an outer ectoderm or epidermis and an inner endoderm or gastrodermis, both of which are formed of epithelio-muscular cells, separated by a non-cellular jelly-like mesoglea. There is a primitive form of nervous system consisting of a net of neurons underlying the epidermis, as well as gastrodermis. Cells unique to cnidarians - the cnidoblasts or nematocytes, with a toxin-laden nematocyst inside - are very specialized, and engage in offence and defense, playing a role in feeding by paralyzing the prey. Hydra consists of three different stem cell lineages, including ectodermal and endodermal epithelial cell lineages, which self-renew by continuous division and migrate towards both the extremities and terminally differentiate. The third stem cell lineage consists of interstitial cells which are multipotent and can differentiate into neurons, secretory cells and 
gametes. In view of the effectively dividing and expanding stem cell lineages, Hydra is practically an immortal organism.

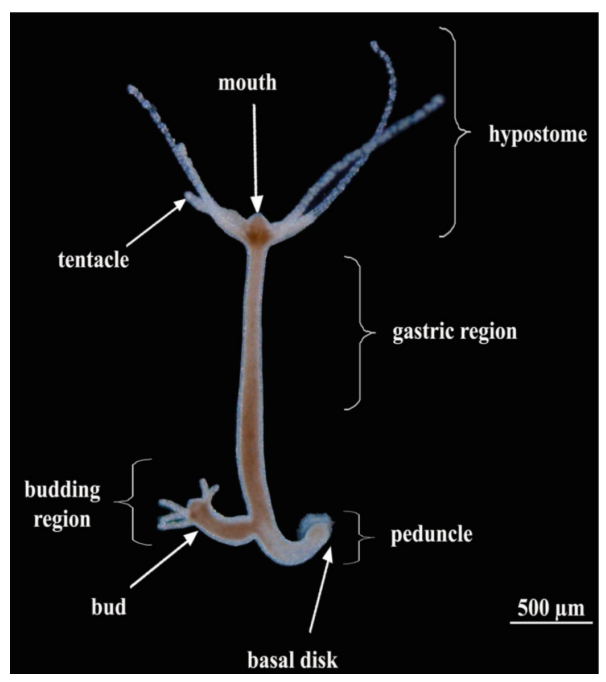

Fig. 1. Morphology of Hydra

\section{Reproduction}

Hydra can reproduce by both sexual and asexual methods. The primary form of reproduction is asexual, by budding, which happens as long as conditions are favorable. Budding results in rapid production of a large number of genetically identical Hydras. This genetic identity enables the researchers to reproduce experimental results with less statistical difference (Beach and Pascoe 1998). Growth rate in Hydra is in equilibrium state between cell proliferation and removal of excess cell by phagocytosis or bud formation (Bosch and David 1984). However, during unfavorable condition or in the context of environmental contamination, the growth rate is affected, and the animal engages in sexual reproduction resulting in cysts that can endure adverse conditions (Ambrosone et al. 2014).

\section{Regeneration}

Hydra is known for its remarkable capability of regeneration. Amputation of Hydra into any number of pieces other than hypostome and basal disc can result in each such piece regenerating the missing parts. It has been stated that Hydra undergoes morphallactic regeneration to restore its unique structure after amputation (Bode 2003). In 
case of head regeneration, wound healing occurs in 3-6 h, the tentacles begin to emerge within 30-36 h, and complete head regeneration occurs within 48-72 h of amputation. Similarly, in case of foot regeneration, epithelial cells extend to heal the wound site and the foot regenerates approximately in $30 \mathrm{~h}$. This dynamic process of regeneration in Hydra is tightly regulated by specific genes. Methods have been developed to quantify the abnormal morphologies as well as alterations in gene expression in Hydra following exposure to an environmental stress, which render Hydra recognized as the ideal model organism to test teratogenicity of environmental pollutants (Wilby 1988; Ambrosone et al. 2014).

\section{End Point Analysis}

\section{Morphological Observation in Hydra Following Exposure to Chemicals}

Toxicity testing in Hydra is manifested by alterations in its morphology, starting with contraction of tentacles and shortening of body column and ending up in animal disintegration. The scoring system for Hydra's morphology was originally designed by Johnson and Gabel (1983), and later improved by Wilby (1988). Thereafter, Wilby's scale of toxicity testing has served as the basis for the determination of toxicity of chemical compounds in Hydra from the perspective of morphological changes. As toxicant concentration increases, progressive changes occur in Hydra's morphology. A score of 10 was assigned to highly intact and healthy polyps, 8 to clubbed tentacles, 6 to shortened tentacles, 5 to tulip phase, 3 and 2 to osmoregulation loss, and 0 to animals that had undergone disintegration (Table 1; Fig. 2). Recently, Ambrosone et al. (2014) observed different phenotypic variations in Hydra when treated with $\mathrm{SiO}_{2}$ nanoparticles, based on which a new scaling system to assess the detrimental effects of nanoparticles in Hydra was devised (Table 2).

Table 1. Scoring system devised by Wilby (1988) for assessing the morphological damage following toxicant exposure.

\begin{tabular}{l|l}
\hline Score & Morphology of polyp \\
\hline 10 & Extended tentacles; body reactive \\
9 & Partially contracted; slow reactions \\
8 & Clubbed tentacles; body slightly contracted \\
7 & Shortened tentacles; body slightly contracted \\
6 & Tentacles and body shortened \\
5 & Totally contracted; tentacles visible \\
4 & Totally contracted; no visible tentacles \\
3 & Expanded; tentacles visible \\
2 & Expanded; no visible tentacles \\
1 & Dead but intact \\
0 & Disintegrated \\
\hline
\end{tabular}




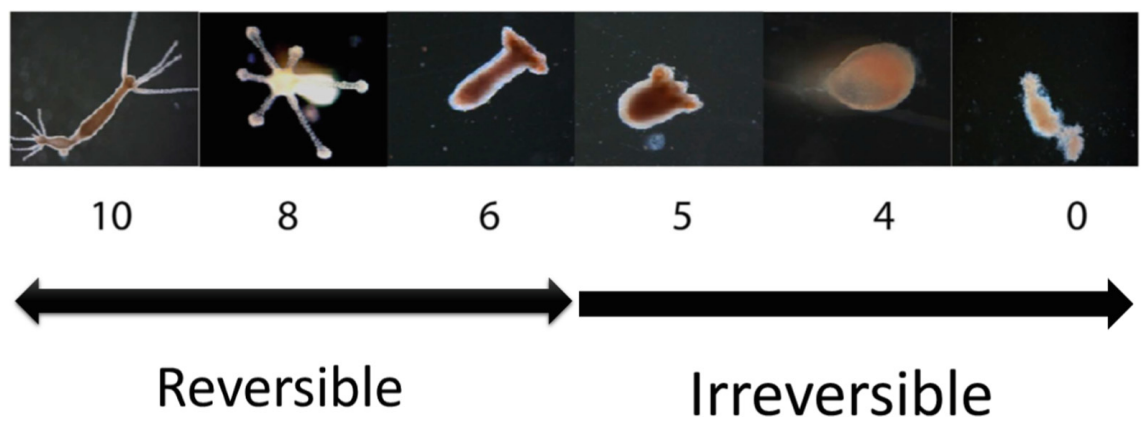

Fig. 2. Representation of Wilby's (1988) scale of toxicity testing for assessing the morphological damage following toxicant exposure. (Adopted from: Murugadas et al. 2016).

Table 2. Scoring system devised by Ambrosone et al. (2014) to measure the morphological traits in hydra following nanoparticle exposure

\begin{tabular}{l|l|l}
\hline Score & Morphology & Vital state \\
\hline 7 & Normal hydra & Active \\
\hline 6 & Bumped gastric regions, normal tentacles & Active \\
\hline 5 & $\begin{array}{l}\text { Inverted-cone gastric regions, } \\
\text { shortened tentacles }\end{array}$ & $\begin{array}{l}\text { Whitening of gastric region; } \\
\text { paralyzed, slow tentacles }\end{array}$ \\
\hline 4 & Inverted-cone gastric regions, short tentacles & Paralyzed, rigid tentacles \\
\hline 3 & Gastric region reduced in size, crushed tentacles & Permanently damaged to death \\
\hline 2 & Further reduced gastric region, without tentacles & Abundant cell death \\
\hline 1 & Irregular shape & Death \\
\hline 0 & Dispersed cell clamps and debris & Disintegrated \\
\hline
\end{tabular}

\section{Methodology}

For aquatic eco-toxicity testing, Hydra is placed at one per $\mathrm{mL}$ of medium $(1 \mathrm{mM}$ $\mathrm{CaCl}_{2}, 1 \mathrm{mM} \mathrm{NaCl}, 0.1 \mathrm{mM} \mathrm{MgSO}, 0.1 \mathrm{mM} \mathrm{KCl}$, and $1 \mathrm{mM}$ Tris- $\mathrm{HCl} ; \mathrm{pH}$ 7.8). Depending on the container capacity, a minimum of 10-25 animals are taken for each experiment, and care is taken to pick those animals which do not possess bud or with only slightly developed bud, to avoid increase in the number of animals at the end of the experiment. For a controlled laboratory experiment, the polyps should be maintained at $18 \pm 1{ }^{\circ} \mathrm{C}$ under $12 \mathrm{~h}$ dark-light cycle. The experiment can be initiated by adding varying concentrations of the chemical substance to the culture dishes and monitoring continuously in a stereo-zoom microscope throughout the study period (72 or $96 \mathrm{~h}$ ). The morphological variations are recorded at regular time intervals. Animals that respond in a specific time are assigned with a median score for determination of median lethal concentration. A score of 5 or less is considered to be lethal and the change is irreversible; in the case of score above 5 the change is reversible, wherein the animal becomes healthy when healthy environment is restored. For a concentrationand/or time-dependent toxicity, the median score is indirectly proportional to the incubation time and concentration tested. 


\section{Impact of Chemicals on Hydra Growth Rate}

Hydra primarily reproduces by budding, which is an asexual method of reproduction. The extent of budding is directly related to food intake. A regular diet maintains the cell proliferation and budding process, whereas budding ceases when starved. In view of a regular feeding regime, the epithelial cell lineage that migrates towards both extremities contributes to bud formation in the gastric region. Thus, growth rate of Hydra is a balance between length of epithelial cell cycle, phagocytosis of the excess cells, and/or bud formation (Bosch and David 1984). Quality of the environment, including chemical contamination, affects the growth rate in Hydra (Lenhoff and Brown 1970).

\section{Methodology}

To measure the growth rate of Hydra, four Hydras each with one bud are exposed to sub-lethal doses of chemical entities for a study period ( $24 \mathrm{~h}$ in case of acute toxicity), and then washed and placed in multi-well plates, preferably as one Hydra per well. Control polyps at the same developmental stage are left untreated and maintained separately. Both treated and untreated Hydras are fed regularly atleast for two weeks and monitored every day for bud detachment. The growth rate constant $(\mathrm{K})$ is measured using the formula $\mathrm{K}=\ln \left(\mathrm{n} / \mathrm{n}_{0}\right) / \mathrm{T}$, where $\mathrm{n}$ is the number of animals at time $\mathrm{T}$ (day of experiment), $\mathrm{n}_{0}$ is the number animals at time $\mathrm{t}_{0}$, i.e., starting day of the experiment; budding rate is calculated as the average number of buds detached per Hydra per day; $\mathrm{T} 2$, the population doubling time, is calculated by linear regression (Ambrosone et al. 2012).

\section{Impact of Chemicals on Hydra's Regeneration Ability}

Hydra is known for remarkable capability of regenerating missing body parts. Hydra undergoes morphallactic regeneration where the tissue left over in a bisected region is remodeled to regenerate the missing body structure. Though Hydra has three different cell lineages, regeneration is taken care by the two epithelial cell lineages. Head regeneration is rapid after bisection of the tubular body column, wherein complete regeneration occurs within $72 \mathrm{~h}$.

Teratogenicity testing in Hydra was initially described by Johnson and Gabel (1983) using dissociated cells of Hydra. Later, Wilby (1988) recommended a new scale to measure the regeneration of Hydra using gastric region. More recently, Ambrosone et al. (2012) proposed a new scale to measure head regeneration in Hydra in the presence of nanoparticles. Here, in the present review, we have summarized the methods of Ambrosone et al. (2012), and Wilby (1988) to measure the regeneration capability of Hydra.

\section{Methodology}

(i) Ambrosone et al. (2012): To measure the effect of toxicant on Hydra's head regeneration capability, groups of polyps are bisected in the upper gastric region and the body column is allowed to regenerate the missing head region in the presence of sub-lethal concentrations of the toxicant. Polyps that undergo head regeneration are examined in a stereo-zoom dissecting microscope at regular time intervals for $72 \mathrm{~h}$, and 
(a)

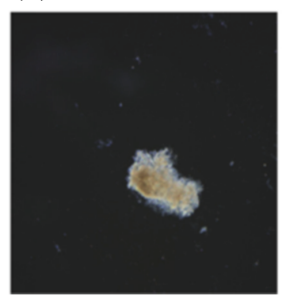

Lethal (or) disintegrated

(b)

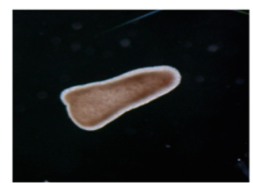

Normal wound healing (3)

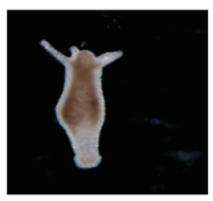

(7) Mouth, $<4$ tentacles

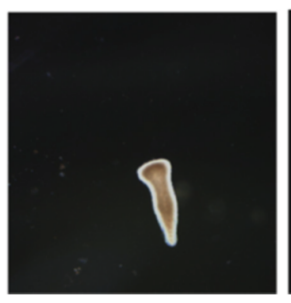

0

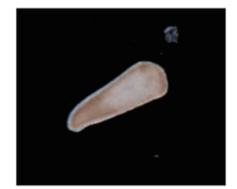

Basal disk only (4)

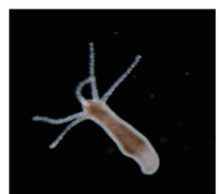

(8) Mouth, basal disc, $<4$ tentacles

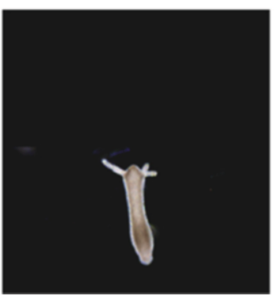

1

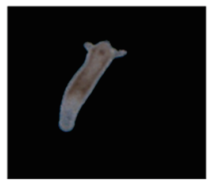

Tentacle buds only

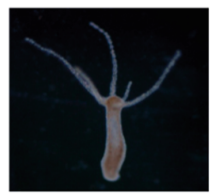

(9), Mouth, 4-6 tentacles

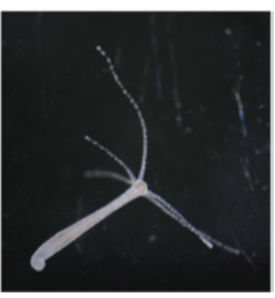

2

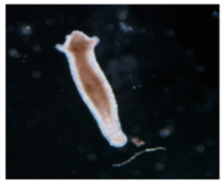

Tentacle buds and basal disk (6)

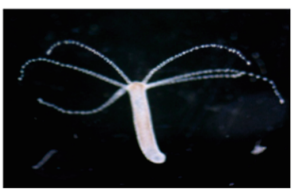

(10) Mouth, 4-6 tentacles, peduncle

Fig. 3. a. Hydra images representing the scoring system devised by Ambrosone et al. (2012) to measure the head regeneration in hydra (Adopted from Murugadas et al. 2016). b. Hydra images representing the scoring system devised by Wilby (1988) for assessing the toxicant induced inhibition of regeneration of gastric region. (Adopted from Zeeshan et al. 2016)

Table 3. Scoring system devised by Ambrosone et al. (2012) to measure the head regeneration in hydra

\begin{tabular}{l|l}
\hline Score & Degree of regeneration \\
\hline 0 & Lethal or disintegrated \\
\hline 1 & No regeneration \\
\hline 2 & Emergence of tentacles \\
\hline 3 & Complete head regeneration \\
\hline
\end{tabular}

score is assigned based on the regeneration. As seen in Fig. 3a and Table 3, score 0 stands for no regeneration, 1 for emergence of tentacles, 2 for complete head regeneration; lethal and disintegration can also be observed.

(ii) Wilby (1988): To measure the chronic toxic effect of a toxicant on Hydra regeneration, groups of polyps are cut below the hypostome and above the budding 
region to separate the gastric region, and allowed to regenerate the missing body portion in the presence of sub-lethal concentrations of the chemical to be tested and the medium is renewed daily. Initially, the wound healing occurs within 3-6 h and the emergence of tentacles and basal disc occurs within $36-48 \mathrm{~h}$. The regeneration is recorded at every $24 \mathrm{~h}$ until $72 \mathrm{~h}$ of amputation. Score of 10 indicates complete regeneration and 0 represents mortality; scores from 9 to 1 express various stages of regeneration (Fig. 3b; Table 4).

Table 4. Scoring system of Wilby (1988) for assessing the toxicant-induced inhibition of regeneration of gastric region

\begin{tabular}{c|l}
\hline Score & Degree of regeneration \\
\hline 10 & Mouth, 4-6 tentacles and peduncle \\
\hline 9 & Mouth, 4-6 tentacles \\
\hline 8 & Mouth, $<4$ tentacles and basal disc \\
\hline 7 & Mouth and $<4$ tentacles \\
\hline 6 & Tentacle buds and basal disc \\
\hline 5 & Tentacle buds only \\
\hline 4 & Basal disc only \\
\hline 3 & Normal wound healing at both ends of gastric region \\
\hline 2 & Healed but body expanded \\
\hline 1 & Open ends of gastric region/dissected region; not healed or dead \\
\hline 0 & Disintegrated \\
\hline
\end{tabular}

However, in most cases, impairment of regeneration in Hydra at sub-lethal concentrations is due to the general toxicity as the chemicals/nanoparticle (NPs) can easily gain access into the Hydra cells via nick at either ends and induce toxicity by increasing the ROS level or sudden exposure of amputated region to a high concentration of chemicals/NPs can induce cell death.

\section{Impact of Chemicals on Hydra Cell Cycle}

Hydra as a whole organism possesses different cell types from three different lineages (Siebert et al. 2008). The cell cycle of interstitial cells is shorter than that of the epithelial cells. However, both cell lineages exhibit a similar regulation of cell cycle with a pause in G2 phase and lack of G1 phase (Buzgariu et al. 2014). Pausing of G2 makes Hydra a potential model to study the impact of pausing of G2 impinging on regenerative competence. Two major challenging tasks in analyzing the cell cycle of a multicellular organism are, (i) to dissociate the complex cell types into individual cells, and (ii) to sort the cells of a similar type based on the marker genes. Cell cycle analysis overcoming these challenges is still possible, taking advantage of the latest advancements in technologies, and it helps in determining the detrimental effects of chemical entities and also in designing new drugs. 


\section{Methodology}

The simplest and most convenient way to dissociate Hydra is to adopt trypsin digestion. After incubation with the toxicant Hydras are rinsed in fresh medium and dissociated in $250 \mu \mathrm{L}$ of trypsin-EDTA for 5-7 min at $37^{\circ} \mathrm{C}$. Trypsin is inactivated by addition of $100 \mu \mathrm{L}$ of fetal calf serum (FCS) to the cell suspension. The cells, at $5 * 10 \% / \mathrm{mL}$, are fixed in $4 \%$ paraformaldehyde and permeabilized using $70 \%$ ethanol. Cells are then stained with $500 \mu \mathrm{L}$ of hypertonic NP-40 buffer [Propidium Iodide (PI)] $40 \mu \mathrm{g} / \mathrm{mL}$, RNase A $200 \mu \mathrm{g} / \mathrm{mL}, 0.5 \% \mathrm{NP}-40$ in PBS), for 15-30 min. The fluorescence emission is measured (Buzgariu et al. 2014) on a FACS Calibur II System (Becton-Dickinson) using an argon-ion laser at $488 \mathrm{~nm}$, together with the forward scattered (FSC) and side scattered (SSC) parameters. The emitted PI fluorescence is collected by a $585 \mathrm{~nm}$ band pass filter in the FL2 channel. Typically 10,000 events per sample are collected using the Cell Quest software, and analyzed with FlowJo software (Tree Star Inc) after excluding debris, clumps (FSC versus SSC) and doublets (signal area FL2-A versus signal width FL2-W).

\section{Assessment of Cell Death in Hydra by ROS Generation and Apoptosis}

Owing to the continuous proliferation of stem cells, excess or dead cells from Hydra are sloughed off by the programmed cell death, i.e. "apoptosis". It is well established that in Hydra apoptotic mode of cell death is conserved (Böttger and Alexandrova 2007). Therefore, Hydra is emerging as an appropriate model organism for drug discovery and biomedical applications. Apoptosis is induced by treatment with chemical substances or under stressful conditions. Oxidative stress sets in as a consequence of imbalance between generation of ROS triggered by external factors and the counteracting antioxidants in the biological system. Excess ROS cause DNA damage and failure of DNA repair mechanism and finally ends up in cell death.

\section{Determination of ROS Generation in Hydra by $\mathrm{H}_{2}$-DCFDA Staining}

Groups of 6 animals per $6 \mathrm{~mL}$ are incubated in medium containing sub-lethal concentrations of the chemical substance to be tested, for the defined period, after which the animals are washed in fresh Hydra medium and incubated with $10 \mu \mathrm{M} \mathrm{H}_{2}$-DCFDA dye for $1 \mathrm{~h}$ in dark as described by Jantzen et al. (1998). After incubation the polyps are rinsed in Hydra medium, mounted on $2 \%$ urethane, and the green punctae are observe immediately in a fluorescent microscope. For quantification of intracellular ROS level, cell lysate is prepared by homogenizing the Hydra in PBS. Protein concentration of the cell lysate is determined using Bradford reagent, with bovine serum albumin (BSA) as the standard. Intracellular ROS level is determined by incubating the cell lysate with $10 \mu \mathrm{M}$ $\mathrm{H}_{2}$-DCFDA dye for $20 \mathrm{~min}$ in dark and the fluorescence is read in a fluorometer.

\section{Determination of Apoptosis by Acridine Orange and DAPI Staining}

\section{Acridine Orange Staining}

Induction of apoptosis at whole animal level can be identified by acridine orange staining as described by Cikala et al. (1999). Groups of 6 animals per $6 \mathrm{~mL}$ are 
incubated in medium containing sub-lethal concentrations of the toxicants to be tested, for the defined period. After incubation polyps are rinsed in Hydra medium and incubated with acridine orange $(3.3 \mu \mathrm{M})$ for 15 min in dark. Polyps are washed adequately with Hydra medium, relaxed in $2 \%$ urethane and the green punctae as apoptotic cells are observed in fluorescent microscope.

\section{4'-6-Diamidino-2-Phenylindole (DAPI) Staining}

Apoptosis as single cells in Hydra can be enumerated following DAPI staining as described by Ambrosone et al. (2012). Groups of 6 animals per $6 \mathrm{~mL}$ are incubated in medium containing sub-lethal concentrations of chemicals for the defined period. Single cell suspensions are prepared by macerating the Hydras and spreading them on gelatin-coated microscopic slides. After adequate wash in PBS the cell suspensions are stained with DAPI for $2 \mathrm{~min}$ and washed in PBS. Cells are examined in a phase contrast fluorescent microscope. Cells, 300-500, are examined for each treatment and the percentage of apoptosis is calculated for both the untreated and treated cells. The comparison is necessary since cells in untreated Hydra also would undergo apoptosis towards maintenance of cell number.

\section{Genotoxicity Assessment in Hydra Following Chemical Exposure}

Genotoxicity assessment in an aquatic invertebrate organism would take it to the level of a good bio-indicator. Chemical substances that affect DNA have serious implications in many pathological conditions such as carcinogenesis and impairment of reproduction. Genotoxicity assessment in a multicellular organism is a challenging task as the organism contains many cell types of different origins. We embarked on dissociation of toxicant-exposed Hydra into individual cells and address the implications of chemical/nanoparticle on DNA in individual cells.

\section{Methodology}

Hydras are treated with sub-lethal concentrations of the intended chemical for the specific period. Hydra could be dissociated into individual cells using trypsin-EDTA or homogenization using a micropipette. In our experience, effective dissociation is possible in trypsin-EDTA digestion (Murugadas et al. 2016). The resulting cell suspension is mixed with low melting agarose in PBS, and placed on microscopic slides coated with normal melting agarose. The slides are placed in pre-chilled lysis buffer (2.5 M NaCl, $100 \mathrm{mM}$ Na2-EDTA, $10 \mathrm{mM}$ Tris, $0.2 \mathrm{mM} \mathrm{NaOH}$ [pH 10], 10\% DMSO and Triton $\mathrm{X}-100)$ and incubated overnight at $4{ }^{\circ} \mathrm{C}$. Alkaline denaturation and gel electrophoresis are performed in cold under dim light in freshly prepared electrophoresis buffer (300 mM NaOH, $1 \mathrm{mM} \mathrm{Na}$-EDTA, [pH > 13]) for $20 \mathrm{~min}$ at $20 \mathrm{~V}$. Then the slides are washed with neutralization buffer $(0.4 \mathrm{M}$ Tris, $\mathrm{pH} 7.5)$ and observed in fluorescent microscope. Three hundred cells from each treatment group are captured and analyzed using CASP software. The extent of DNA damage is measured according as depicted in Fig. 4 and Table 5. 


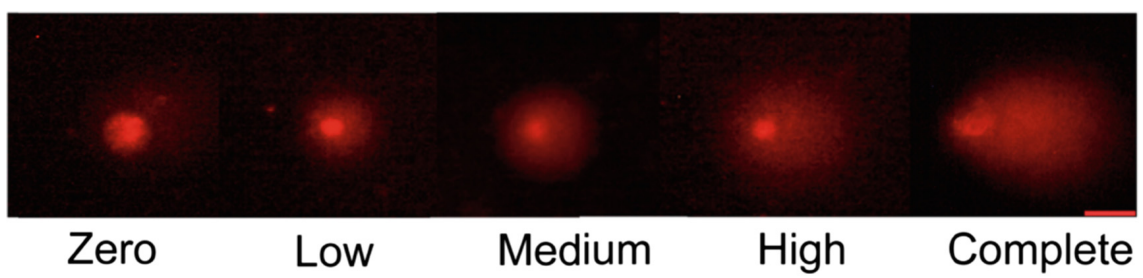

Fig. 4. Images representing the extent of DNA damage as assessed by Comet assay. (Adopted from Zeeshan et al. 2017)

Table 5. Allocation of empirical scores to cells (categorization of DNA damage and score allocation)

\begin{tabular}{l|l|l}
\hline Percentage of DNA damage & Category assigned & Score allocated \\
\hline $0-5$ & Zero & 0 \\
\hline $6-20$ & Low & 1 \\
\hline $21-40$ & Medium & 2 \\
\hline $41-95$ & High & 3 \\
\hline $96-100$ & Complete & 4 \\
\hline
\end{tabular}

\section{Transcriptional Alterations in Hydra Following Chemicals Exposure}

It is well demonstrated that chemicals/heavy metals/nanoparticles can interact with nucleic acids and induce DNA damage and point mutations and alter transcriptional regulation of important genes governing antioxidant defense system and cell death (Woo et al. 2012; Murugadas et al. 2016; Zeeshan et al. 2016, 2017). The whole genome sequencing of Hydra has revealed that it has conserved sequences and signaling pathways of divergent organisms and makes it comparable with the other model organisms. Thus, toxicant-exposed Hydras can be subjected to RNA isolation, cDNA synthesis and qPCR to assess the transcriptional alterations, which we intend to standardize and bring out in our next review.

\section{Conclusion}

In view of varied manifestations of emerging pollutants, risk assessment of the chemical entities before releasing them into the environment is necessary. Hydra as a model organism is easy to culture, multiplies rapidly by asexual reproduction, costeffective, sensitive to inorganic substances, morphological changes can be easily monitored and classified, and genetically identical twins can be made use of for reproducible results at transcriptional levels. Its robust nature of whole body regeneration from the dissociated cells or gastric region or body column makes Hydra a suitable organism for teratogenicity testing. A comprehensive study including various 
end point analyses and expression of biomarker genes can explain the underlying mechanism of toxicity induced by various chemical substances. Thus, Hydra is an organism highly suited for aquatic eco-toxicity testing.

Acknowledgments. The financial support from Doerenkamp-Zbinden Foundation, Switzerland, is heartily acknowledged.

\section{References}

Ambrosone A, Mattera L, Marchesano V et al (2012) Mechanisms underlying toxicity induced by CdTe quantum dots determined in an invertebrate model organism. Biomaterials 33 (7):1991-2000. https://doi.org/10.1016/j.biomaterials.2011.11.041

Ambrosone A, Scotto di Vettimo MR, Malvindi MA et al (2014) Impact of amorphous $\mathrm{SiO}_{2}$ nanoparticles on a living organism: Morphological, behavioral, and molecular biology implications. Front Bioeng Biotechnol 2:37. https://doi.org/10.3389/fbioe.2014.00037

Beach MJ, Pascoe D (1998) Therole of Hydra vulgaris (Pallas) in assessing the toxicity of freshwater pollutants. Water Res 32(1):101-106. https://doi.org/10.1016/S0043-1354(97) 00180-2

Bode HR (2003) Head regeneration in Hydra. Dev Dyn 226(2):225-236. https://doi.org/10.1002/ dvdy. 10225

Bosch TCG, David CN (1984) Growth regulation in Hydra: relationship between epithelial cell cycle length and growth rate. Dev Biol 104(1):161-171. https://doi.org/10.1016/0012-1606 (84)90045-9

Böttger A, Alexandrova O (2007) Programmed cell death in Hydra. Sem Cancer Biol 17(2):134146. https://doi.org/10.1016/j.semcancer.2006.11.008

Buzgariu W, Crescenzi M, Galliot B (2014) Robust G2 pausing of adult stem cells in Hydra. Differentiation 87(1):83-99. https://doi.org/10.1016/j.diff.2014.03.001

Cattaneo A, Gornati R, Chiriva-Internati M, Bernardini G (2009) Ecotoxicology of nanomaterials: the role of invertebrate testing. Exposure 6:78-97

Cikala M, Wilm B, Hobmayer E, Böttger A, David CN (1999) Identification of caspases and apoptosis in the simple metazoan Hydra. Curr Biol 9(17):959-962. https://doi.org/10.1016/ S0960-9822(99)80423-0

Geissen V, Mol H, Klumpp E et al (2015) Emerging pollutants in the environment: a challenge for water resource management. Int Soil Water Conserv Res 3(1):57-65. https://doi.org/10. 1016/j.iswcr.2015.03.002

Hecker B, Slobodkin LB (1976) Responses of Hydra oligactis to temperature and feeding rate. In: Mackie GO (ed) Coelenterate ecology and behavior. Springer, Boston, MA, pp 175-183. https://doi.org/10.1007/978-1-4757-9724-4_19

Herricks EE, Schaeffer DJ (1985) Can we optimize biomonitoring? Environ Manag 9(6):487492. https://doi.org/10.1007/bf01867323

Jantzen H, Hassel M, Schulze I (1998) Hydroperoxides mediate lithium effects on regeneration in Hydra. Comp Biochem Physiol C Pharmacol Toxicol Endocrinol 119(2):165-175. https://doi. org/10.1016/S0742-8413(97)00204-1

Johnson EM, Gabel BEG (1983) An artificial 'Embryo' for detection of abnormal developmental biology. Fundam Appl Toxicol 3(4):243-249. https://doi.org/10.1016/S0272-0590(83)80135-3

Krewski D, Acosta D, Andersen M et al (2010) Toxicity testing in the 21st century: a vision and a strategy. J Toxicol Env Health B Critical Rev 13:51-138. https://doi.org/10.1080/10937404. 2010.483176 
Lenhoff HM, Brown RD (1970) Mass culture of Hydra: an improved method and its application to other aquatic invertebrates. Lab Anim 4(1):139-154. https://doi.org/10.1258/ 002367770781036463

Marchesano V, Ambrosone A, Bartelmess J et al (2015) Impact of carbon nano-onions on Hydra vulgaris as a model organism for nanoecotoxicology. Nanomaterials 5(3):1331-1350

Murugadas A, Zeeshan M, Thamaraiselvi K, Ghaskadbi S, Akbarsha MA (2016) Hydra as a model organism to decipher the toxic effects of copper oxide nanorod: eco-toxicogenomics approach. Sci Rep 6:29663. https://doi.org/10.1038/srep29663

Patwardhan V, Ghaskadbi S (2013) Invertebrate alternatives for toxicity testing: hydra stakes its claim. Altex Proc 2(1):69-76

Quinn B, Gagné F, Blaise C (2008) The effects of pharmaceuticals on the regeneration of the cnidarian, Hydra attenuata. Sci Total Environ 402(1):62-69. https://doi.org/10.1016/j. scitotenv.2008.04.039

Siebert S, Anton-Erxleben F, Bosch TCG (2008) Cell type complexity in the basal metazoan Hydra is maintained by both stem cell based mechanisms and trans differentiation. Dev Biol 313(1):13-24. https://doi.org/10.1016/j.ydbio.2007.09.007

Wilby OK (1988) The Hydra regeneration assay. In: Proceedings of Assoc Francaise de Teratologie, pp 108-124

Woo S, Lee A, Won H, Ryu J-C, Yum S (2012) Toxaphene affects the levels of mRNA transcripts that encode antioxidant enzymes in Hydra. Comp Biochem Physiol C Toxicol Pharmacol 156(1):37-41. https://doi.org/10.1016/j.cbpc.2012.03.005

Zeeshan M, Murugadas A, Ghaskadbi S, Rajendran BR, Akbarsha MA (2016) ROS dependent copper toxicity in Hydra- Biochemical and molecular study. Comp Biochem Physiol C Toxicol Pharmacol 185-186(Supplement C):1-12. doi:https://doi.org/10.1016/j.cbpc.2016. 02.008

Zeeshan M, Murugadas A, Ghaskadbi S, Ramaswamy BR, Akbarsha MA (2017) Ecotoxicological assessment of cobalt using Hydra model: ROS, oxidative stress, DNA damage, cell cycle arrest, and apoptosis as mechanisms of toxicity. Environ Pollut 224(Supplement C):5469. doi:https://doi.org/10.1016/j.envpol.2016.12.042

Open Access This chapter is licensed under the terms of the Creative Commons Attribution 4.0 International License (http://creativecommons.org/licenses/by/4.0/), which permits use, sharing, adaptation, distribution and reproduction in any medium or format, as long as you give appropriate credit to the original author(s) and the source, provide a link to the Creative Commons licence and indicate if changes were made.

The images or other third party material in this chapter are included in the chapter's Creative Commons licence, unless indicated otherwise in a credit line to the material. If material is not included in the chapter's Creative Commons licence and your intended use is not permitted by statutory regulation or exceeds the permitted use, you will need to obtain permission directly from the copyright holder.

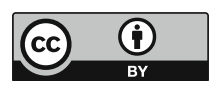

